\title{
Similarities and Differences between Simultaneous and Successive Bilingual Children: Acquisition of Japanese Morphology
}

\author{
Yuki Itani-Adams ${ }^{1}$, Junko Iwasaki², Satomi Kawaguchi ${ }^{3 *}$ \\ ${ }^{1}$ ANU College of Asia \& the Pacific, The Australian National University, Canberra, ACT, 2601, Australia \\ ${ }^{2}$ School of Arts and Humanities, Edith Cowan University, 2 Bradford Street, Mt Lawley WA 6050, Australia \\ ${ }^{3}$ School of Humanities and Communication Arts, Western Sydney University, Bullecourt Ave, Milperra NSW 2214, Australia \\ Corresponding Author: Satomi Kawaguchi, E-mail: S.Kawaguchi@westernsydney.edu.au
}

\section{ARTICLE INFO \\ Article history \\ Received: June 14, 2017 \\ Accepted: August 14, 2017 \\ Published: December 01, 2017 \\ Volume: 6 Issue: 7 \\ Special Issue on Language \& Literature Advance access: September 2017}

Conflicts of interest: None Funding: None

\begin{abstract}
This paper compares the acquisition of Japanese morphology of two bilingual children who had different types of exposure to Japanese language in Australia: a simultaneous bilingual child who had exposure to both Japanese and English from birth, and a successive bilingual child who did not have regular exposure to Japanese until he was six years and three months old. The comparison is carried out using Processability Theory (PT) (Pienemann 1998, 2005) as a common framework, and the corpus for this study consists of the naturally spoken production of these two Australian children. The results show that both children went through the same developmental path in their acquisition of the Japanese morphological structures, indicating that the same processing mechanisms are at work for both types of language acquisition. However, the results indicate that there are some differences between the two children, including the rate of acquisition, and the kinds of verbal morphemes acquired. The results of this study add further insight to an ongoing debate in the field of bilingual language acquisition: whether simultaneous bilingual children develop their language like a first language or like a second language.
\end{abstract}

Key words: Simultaneous Bilingual Language Acquisition, Successive Language Acquisition, Japanese Morphology, Processability Theory

\section{INTRODUCTION}

Do children who acquire more than one language simultaneously from birth develop each language like monolingual first language (L1) learners, or like second language (L2) learners? This question has drawn much attention in the field of simultaneous bilingual language acquisition. Past studies have found that the two languages of simultaneous bilingual children can indeed be acquired independently from each other, like two first languages (e.g., De Houwer 1990, 1995, 2005, 2009 for summary of past research; Lanza 1997; Meisel 1990, 2001; Mishina-Mori 2002; Paradis \& Genesee 1996). These studies have concluded that simultaneous bilingual children develop their languages like L1, based on the following findings: (1) simultaneous bilingual children differentiate the two languages from very early on, through use of the appropriate language in a specific language context; (2) no systematic transfer of linguistic properties from one language to the other was demonstrated; (3) based on findings that bilingual children did not show any delay or acceleration in timing of acquisition of certain grammatical structures compared to the L1 children, simultaneous bilingual children follow the same developmental paths as the L1 children in terms of morphology and syntax. The findings from these studies support the Separate Development Hypothesis (SDH) proposed by De Houwer (1990).
Schlyter (1993), however, points out that such resemblance between bilingual and monolingual children was found when a comparison was made using the data from so-called balanced bilinguals. Not all simultaneous bilingual children develop to be a balanced bilingual. This notion of balance between the two languages has led to the notion of 'stronger' and 'weaker' languages. There is a debate about what the term 'balance' refers to in the context of the development of two languages (see Meisel 2004 and 2007 for discussion) and how to determine the balance between two languages. In the existing literature (e.g. Schlyter 1993; Döpke 1996; Jisa 2000) balance is often defined by the comparison of the mean length of utterance (MLU) values of the two languages against the child's age; the language possessing a lower MLU at the same age is labeled the 'weaker' language.

Schlyter (1993) and Schlyter and Håkansson (1994) investigated how Swedish-French bilingual children developed their weaker language (Swedish). The verb-second (V2) word order of Swedish was the structure examined in both studies. ${ }^{1}$ Schlyter (1993) concludes "the stronger language of a bilingual child is exactly like a normal first language in monolingual children, whereas the weaker language in these respects has similarities with a second language" (p. 305). This is also supported by Schlyter and Håkansson (1994). 
Döpke (1996) re-examined the nature of the development of the weaker language (German) of bilingual children acquiring German and English from birth. She found that while their German showed some similarities to German $\mathrm{L} 1$, it also showed variations that did not occur in L1 data. Furthermore, these variations were similar to some of the phenomena occurring in German L2 acquisition. From this, Döpke (1996) argues that the weaker language of bilingual children is unlike either L1 or L2, but rather creates "a bridge between L1 and L2” (p. 18). Other researchers (e.g., Hulk \& Müller 2000; Yip \& Matthews 2000, 2007) also present similar phenomena in the bilingual children they studied with different language combinations.

The above-mentioned studies compared data from different studies that investigate the acquisition of the same language. There are a number of methodological issues to be considered when comparing results from different studies. As pointed out by Håkansson (2005), the "differences in theoretical paradigms, views on what counts as reliable data, acquisition criteria and which linguistic areas to measure" (p.179) make comparisons between different types of acquisition a complex task. Further past studies compared linguistic representation by bilingual children to other types of language acquisition, and used them as evidence to differentiate between different types of language acquisition. These studies did not search for evidence in terms of the language acquisition process.

Our study addresses the issue of the nature of bilingual language development, focusing on the relationships between the simultaneous bilingual and L2. We compare the development of Japanese morphology between a balanced simultaneous bilingual child and a successive bilingual child who acquired Japanese as L2. The first child in this study received Japanese input from birth, together with English, in a one-parent one-language environment (Döpke 1992). This child developed her two languages in a balanced manner. The second child received his Japanese input sequentially to his English L1, starting from age 6;03 (six years and three months) at a Japanese school in Australia. In order to address one of the methodological issues mentioned above about making comparison between different sets of data, we use the same theoretical framework to compare the two children's data. The comparison uses Processability Theory (PT) (Pienemann 1998, 2005; Pienemann \& Keßler 2011), a tried and tested transitional paradigm, as a common point of reference. The next section describes PT and its predicted developmental schedule for Japanese morphology.

\section{Processability Theory (PT) and Japanese Developmental Schedule}

PT is a transition theory which views acquisition of language as the acquisition of specific procedural skills needed for processing the target language. The original version of PT (Pienemann 1998) focuses on the acquisition of morphology, while the extension of PT addresses the development of syntax and discourse (e.g. Bettoni \& Di Biase 2015; Pienemann, Di Biase \& Kawaguchi 2005). As our focus in this paper is the acquisition of Japanese morphology, we will limit our description of PT to the acquisition of Japanese morphology (Di Biase \& Kawaguchi 2002) as below.

The theory incorporates the hierarchy of processing procedures described in Levelt's (1989) speech production model, and proposes the universal hierarchy of the acquisition of the procedural skills required for each processing procedure. PT posits that for a language learner, these processing procedural skills will be acquired in the following sequence, from Stage 1 to Stage 5, forming a hierarchy, and that each level of the hierarchy is a prerequisite for the next level (Pienemann 1998).

(1) Stage 1: Word/lemma access;

Stage 2: Category procedure;

Stage 3: Phrasal procedure;

Stage 4: S-procedure;

Stage 5: The subordinate clause procedure, if applicable (from Di Biase \& Kawaguchi 2002)

PT explains morphological structures for each processing procedure in terms of the exchange of grammatical information, based on Lexical Functional Grammar's (LFG) (Bresnan 2001) notion of feature unification. Each processing procedural skill allows a specific type of information exchange between lexicons. Below we explain the types of information exchange required for each stage by presenting Japanese developmental schedule.

Japanese is a SOV (Subject-Object-Verb) language. Japanese word order is flexible; however, verbs are required to be placed in the final position in both the main and subordinate clauses (Shibatani 1990). Japanese uses post-nominal particles to encode the grammatical or semantic functions of arguments, such as the nominative (NOM) marker $-g a$ to mark the grammatical role $\mathrm{SUBJ}(\mathrm{ect})$, the accusative (ACC) marker $-o$ to marks OBJ(ect). An example of use of post-nominal particles is given below in (2).

Japanese verbs are composed of a combination of stem and agglutinative morphemes. The verb stem never occurs on its own. In other words, it is always suffixed by at least one morpheme. For example, the past tense form of the Japanese verb meaning "to eat" is tabe-ta (= ate) and the non-past tense form is tabe-ru (= eat). Tabe-ta (= ate) contains the past tense verb morpheme -ta (PAST) as a suffix of the stem tabe, whereas tabe-ru (= eat) contains the non-past verbal morpheme $-u$ (NONPAST) as a suffix of the same stem. In Japanese, more than one verb can be concatenated successively. When this happens, the finite verb is placed in final position. The first verb must be marked with the complementiser (COMP) -te, forming a V-te $\mathrm{V}$ structure, e.g. kat-te tabe-ru 'buy-COMP eat-NONPAST' (= buy (something) and eat (it)). ${ }^{2}$ Di Biase and Kawaguchi (2002) and Kawaguchi $(2005,2010,2015)$ applied the PT hierarchy to key features of Japanese morphology and proposed the developmental schedule for Japanese as a second language (JSL). The resulting JSL developmental trajectory is presented in Table 1.

In Stage One, word/lemma access, a learner learns words (e.g. inu $(=\mathrm{dog})$, hon (=book)) or memorises chunks (e.g. o-genki desu ka? (=How are you?)). In Stage Two, the category procedure stage, information in lexical entry begins to be annotated. A learner at this stage is not yet able to 
exchange information across words. The structure which is predicted for this stage is verbal morphemes, such as tense (e.g., tabe-ta 'eat-PAST' (= ate), tabe-ru 'eat-NONPAST' $(=$ eat)), aspect, level of politeness (e.g. tabe-mas- $u$ 'eatPOL (ITE)-NONPAST' (= eat)) or polarity (e.g. tabe-nai 'eat-NEG(ative)' (= not eat)).

In Stage Three, phrasal procedure, a learner is able to exchange grammatical information across the lexicon within a phrase. This is when phrasal morphology is predicted to emerge. For Japanese the V-te V (V-COMP V) structure is predicted to be processable at the phrasal procedure stage. According to Sells (1995), the Japanese verbal suffix -te (COMP) carries the information called 'combinatoric TYPE: V-sis' (p.309). This combinatoric TYPE means that the suffix licenses the host word to have $\mathrm{V}$ as a sister. When the $\mathrm{V}$-te $\mathrm{V}$ structure is assembled, the information 'TYPE: $\mathrm{V}$-sis' needs to be unified between the two verbs within a VP(hrase). The next stage, Stage Four, S-procedure, allows a leaner to exchange grammatical information across phrases. This is when interphrasal morphology is predicted to emerge. For Japanese, the agreement of nominal markers and verbal morphemes in the predicate can be processed. One realisation of this type of agreement is the suffixation of the dative marker - $n i$ (DAT) in the oblique argument (OBL) in benefactive (BENE), passive (PASS) and causative (CAUSE) constructions. Di Biase and Kawaguchi (2002) argued that these structures involve interphrasal operations 'because these structures require information exchange across phrases in the grammatical encoding process' (p. 294). We will briefly explain this using the benefactive structure outlined below.

The benefactive structure involves the verbs for giving and receiving kureru (= give (me)), ageru (= give (somebody)) or morau (= (I) receive). These verbs can be used as a single verb to indicate the giving and receiving of objects. However, they can also be used as the second verb in the concatenated verb structure $\mathrm{V}$-te $\mathrm{V}$ to express the giving or receiving of an action expressed by the first verb, e.g. katte ageru 'buy-COMP give' (= (someone) buy (something for someone else)). The agreement between the suffixation of $-n i$ (DAT) in the oblique argument and verb morphology is illustrated using examples $(3 a, b)$ below. When the verb for giving is used, the agent is marked as subject with the suffix -ga (NOM) (Yoshiko-ga in 3a), and the beneficiary/ recipient is marked as OBL with -ni (DAT) (Keiko-ni in 3a). However, when the verb for receiving is used, the beneficiary/recipient is the SUBJ marked -ga (NOM) (Keiko-ga in $3 \mathrm{~b}$ ) and the agent is an oblique argument (OBL) marked $-n i$ (DAT) (Yoshiko-ni in 3b).

$\begin{array}{llllll}\text { (3a) } & \text { Yoshiko-ga } & \text { Keiko-ni } & \text { ringo-o } & \text { kat-te } & \text { age-ta } \\ & \text { Yoshiko- } & \text { Keiko- } & \text { apple- } & \text { buy- } & \text { give-PAS } \\ \text { NOM } & \text { DAT } & \text { ACC } & \text { COMP } & \\ & \text { 'Yoshiko bought an apple and gave it to Keiko.' } \\ \text { (3b) } & \text { Keiko-ga } & \text { Yoshiko-ni } & \text { ringo-o } & \text { kat-te } & \text { morat-ta } \\ & \text { Keiko- } & \text { Yoshiko- } & \text { apple- } & \text { buy- } & \text { receive- } \\ \text { NOM } & \text { DAT } & \text { ACC } & \text { COMP } & \text { PAST }\end{array}$

'Keiko received an apple bought by Yoshiko.'

The acquisition criteria used in PT is the emergence criteria. PT determines the first productive usage of a certain linguistic structure to be the temporal point of acquisition of that structure. The productivity is examined by a distributional analysis of lexical and form variations of the structure in question (see Pienemann 1998 for a detailed summary of acquisition criteria). Following the processing procedure hierarchy, PT predicts that a language learner develops Japanese morphology in the order of Lemma $<$ Verbal morphemes $<\mathrm{V}$-te $\mathrm{V}<$ Agreement between noun marking and the predicate in BENE, CAUSE and PASS structures.

As PT is based on the acquisition of a cognitive processing procedure, Pienemann (1998) claims its hypothesis to be universal across languages. This universal applicability of PT has been empirically tested for a number of typologically different languages such as German, Italian, Japanese, Mandarin Chinese, Swedish, for both adult and child, including

Table 1. Developmental schedule of Japanese in PT framework (Adapted from Di Biase \& Kawaguchi, 2002; Kawaguchi, 2005, 2010, 2015)

\begin{tabular}{|c|c|c|c|c|}
\hline Stage & $\begin{array}{l}\text { Processing } \\
\text { procedures }\end{array}$ & L2 processes & Japanese morphology & Examples \\
\hline 4 & S-procedure & $\begin{array}{l}\text { Interphrasal } \\
\text { morphology }\end{array}$ & $\begin{array}{l}\text {-Agreement between noun } \\
\text { marking and the predicate } \\
\text { in benefactive (BENE), } \\
\text { causative (CAUSE) and } \\
\text { passive (PASS) structures }\end{array}$ & $\begin{array}{l}\text { Keiko-wa Yoshiko-ni ringo-o kat-te-morat-ta. } \\
\text { (=Keiko received an apple bought by Yoshiko.) }\end{array}$ \\
\hline 3 & Phrasal procedure & $\begin{array}{l}\text { Phrasal } \\
\text { morphology }\end{array}$ & -V-te V (V-COMP V) & $\begin{array}{l}\text {-kat-te tabe-ru } \\
\text { (=buy (something) and eat (it)) }\end{array}$ \\
\hline 2 & Category procedure & $\begin{array}{l}\text { Lexical } \\
\text { morphology }\end{array}$ & -Verbal morphemes & $\begin{array}{l}\text { tabe-ta (=ate), } \\
\text { tabe-ru (=eat) } \\
\text { tabe-nai (=no eat) } \\
\text { tabe-te (=please eat) } \\
\text { tabe-chatta (=have eaten, complete) } \\
\text { tabe-teru (=am/is eating, progressive) }\end{array}$ \\
\hline 1 & Word/lemma access & $\begin{array}{l}\text { Words, } \\
\text { Formulae }\end{array}$ & $\begin{array}{l}\text {-Invariant form } \\
\text {-Formulaic expression }\end{array}$ & \\
\hline
\end{tabular}


simultaneous bilingual child language acquisition (see Bettoni \& Di Biase, 2015; Kessler \& Keatinge 2009; Mansouri 2007; Pienemann 2005, Pienemann \& Keßler 2011 for details of the acquisition of different languages).

\section{THE STUDY}

\section{Study Design and Research Question}

This study compares the development of Japanese morphology of a balanced simultaneous bilingual, Haru ${ }^{3}$, who acquired Japanese as L1 against the successive bilingual child, John, who acquired Japanese as L2. The corpus for Haru is taken from Itani-Adams (2013), and the corpus for John is from Iwasaki (2008), both extensive longitudinal studies. The target structures for analysis are: verbal morphemes (e.g. -ta (PAST), -ru (NONPAST), -nai (NEG), -te (REQ)), $\mathrm{V}$-te $\mathrm{V}$ structure, and agreement between noun marking and predicate in BENE, CAUSE and PASS structures presented for each developmental stages Table 1 above.

The acquisition of each structure within respective corpus was determined using PT. The point of acquisition was determined by emergence criteria. To examine the emergence, a frequency count and distributional analysis for each structure were conducted to determine the first productive usage of the structure in question. These structures were then sequenced according to PT's developmental schedule. Following this, the comparison between Haru and John's developmental sequences and rates was carried out. The use of PT allows the comparison of the data of these two children, for the development of linguistics structures require identical processing skills between the two children.

The research question of the study is as follows:

(RQ) do balanced simultaneous bilingual children develop their Japanese verbal morphology in a similar way to successive bilingual children?

\section{Informants and Data for the Study}

The corpus for this study consists of the naturally spoken production of two Australian children: Haru and John. As mentioned above, Haru was brought up bilingually from birth in a one-parent one-language environment. Haru's mother is a native speaker of Japanese and her father, a native speaker of English. As a young child, Haru's mother spoke to her in Japanese, while her father spoke to her in English. The language used between her parents is English, and the family live in an environment where English is the predominant language used within the community.

The other child, John, is a monolingual English speaking child who learnt Japanese in a natural environment, while attending a day school for Japanese children in Australia. His parents are both English-speaking Australian, and John is their second son. The family, consisting of John's parents and his older brother by three and a half years, lived in Japan for four years prior to John's birth, which took place in Australia. The family continued to live in Japan for a further two years after his birth. When John was two years old, the family returned to Australia permanently.
It is possible that John received a certain amount of exposure to Japanese while living in Japan during his first two years of his life. However, an interview with his mother revealed that the language spoken within the family was English, and as he was too young to attend school, the language input directed at John was predominantly English. Further, during an interview with John's Japanese school teacher, one of the authors was informed that John had no Japanese proficiency at the time of first enrolling at his Japanese school.

The Japanese School attended in Australia by John is a private school consisting of both primary and lower secondary levels. The school uses the curriculum prescribed by the Japanese Ministry of Education and Science (Monbukagaku-sho), and aims to provide its students with a standard of education equivalent to that in Japan. It was established and approved by both the Japanese and Australian Governments. The majority of the students at the school are children whose parent or parents are Japanese; however, the school is also open to the local community, allowing non-Japanese background children to enrol. No instruction for Japanese as a second language is provided for such children, and John learned Japanese in a naturalistic manner. In the interview with one of the authors, John's teacher recalled that it took approximately three months before John produced a Japanese word spontaneously, and a further six to seven months before he began to produce large amounts of Japanese.

For both Haru and John, data was collected by audio- and/or video- recorded interaction between the child and other speakers of Japanese. The recorded data was then transcribed orthographically for analysis. Data for Haru was collected over a three year period, from the time she was $1 ; 11$ until 4;10. In each recording session, Haru's interaction with a Japanese-speaking adult was recorded for 45 mins. Data from every monthly recording session in the first year, and every three months in the second and third year (in total 21 sessions), was used for analysis.

Data for John was collected for one year and nine months, from the time he was 7;0 until he was 8;09. In John's case, data collection began nine months after he was first exposed to Japanese at his Japanese school. His data collection lasted for 90 minutes at a time and was conducted fortnightly. In total, data from 26 sessions, including 24 fortnightly sessions in the first year and two follow-up recording sessions in the second year, was used for analysis. With John, tasks such as 'spot the difference' and 'picture description' were used to elicit spontaneous Japanese output. The linguistic analysis was based on 7054 unilingual Japanese turns (i.e. turns that consists of solely Japanese words) in Haru's, data, and 9994 turns in John's data.

The balance between Haru's two languages is shown in her vocabulary size (Figure 1) and MLU (Figure 2). These figures show that Haru's two languages continued to develop during the period of investigation in a similar manner, in terms of vocabulary and MLU. Between the two languages, it can be observed that towards the end of the period of investigation, her Japanese contained more vocabulary and higher MLU than her English. 


\section{RESULTS AND DISCUSSION}

This section first presents the results of developmental paths found in the two children. It then proceeds to compare these two children's development, and discuss the findings.

\section{Development of Japanese morphology of two children}

The developments of Japanese morphology of the two children are presented in Table 2 for Haru, and Table 3 for John (below). In these tables, the dotted lines indicate the time of emergence for each structure. The three numbers with slashes in the interphrasal morphology represent different types of tokens. The figures before the first slash indicate cases of sufficient evidence, the one between the slashes insufficient evidence, and the one after the second slash negative evidence.

Haru was already at the one-word stage when the data collection began at $1 ; 11$; in other words, she had already reached the word/lemma stage. Haru's lexical morphology, i.e. verbal morphemes, emerged when she was $2 ; 2$ (Session 4), the phrasal morphology, i.e., the V-te V structure at 2;9 (Session 12). The interphrasal morphology realised by one case of non-canonical case marking in the benefactive structure emerged last when she was 4;10 (Session 38). There were some occurrences of lexical morphology prior to Session 4, and phrasal morphology prior to Session 12; however, in each of the cases, the productivity was not de-

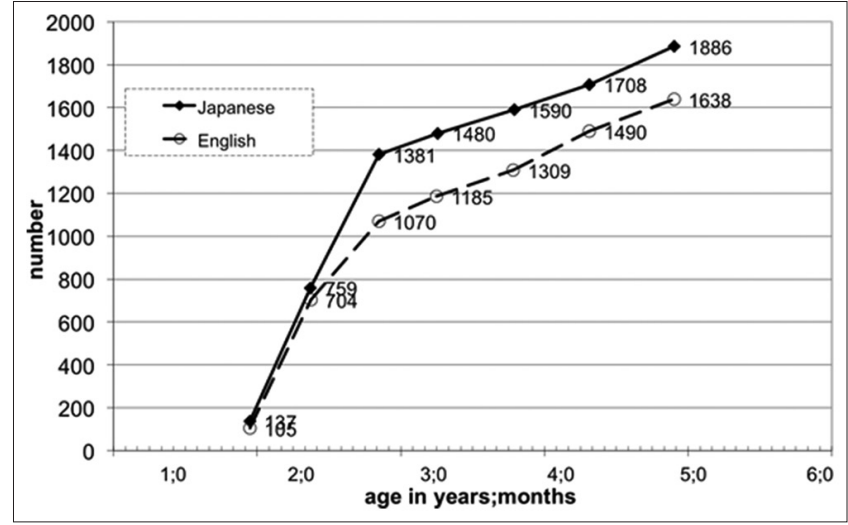

Figure 1. Haru's Japanese and English vocabulary size

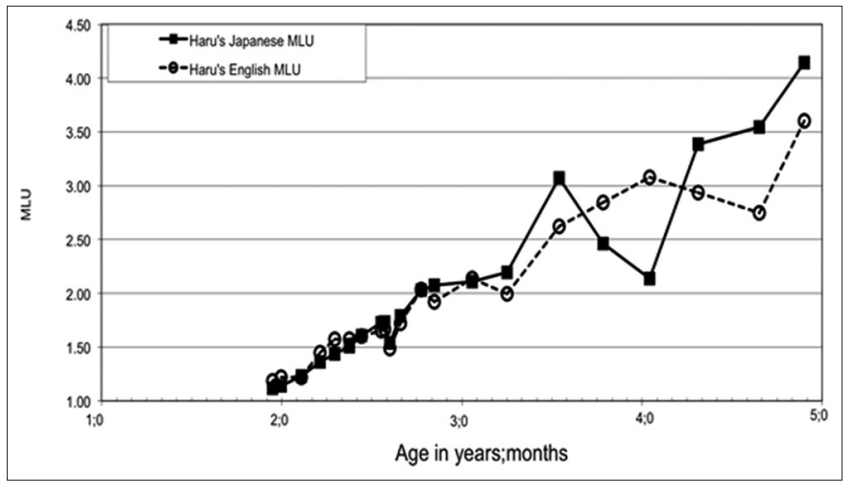

Figure 2. Haru's Japanese and English MLU

Table 2. Haru's development of Japanese morphology

\begin{tabular}{|c|c|c|c|c|c|c|c|c|c|c|c|c|c|c|c|c|c|c|c|c|c|}
\hline $\begin{array}{l}\text { Session } \\
\text { Stage }\end{array}$ & 1 & 2 & 3 & 4 & 5 & 6 & 7 & 8 & 9 & 10 & 11 & 12 & 13 & 16 & 19 & 22 & 25 & 28 & 31 & 34 & 38 \\
\hline $\begin{array}{l}\text { Intexphrasal: Non- } \\
\text { canonical case marking } \\
\text { Causative } \\
\text { Passive } \\
\text { Beacfactixc }\end{array}$ & & & & & & & & & & & & & & & & & & & & & $1 / 0 / 0$ \\
\hline $\begin{array}{l}\text { Phrasal } \\
\text { V-te V } \\
\text { Lexical }\end{array}$ & & & & & & & 1 & & & & & 2 & 12 & & 1 & 2 & 4 & & 5 & 12 & 12 \\
\hline $\begin{array}{l}-t e \text { (request) } \\
-\mathrm{ear}\end{array}$ & (1) & & $\begin{array}{l}2 \\
5\end{array}$ & $\begin{array}{l}6 \\
3\end{array}$ & $\begin{array}{r}11 \\
2\end{array}$ & 14 & $\begin{array}{r}15 \\
2\end{array}$ & 15 & $\begin{array}{r}12 \\
6\end{array}$ & $\begin{array}{r}29 \\
4\end{array}$ & $\begin{array}{r}25 \\
1\end{array}$ & $\begin{array}{l}32 \\
15\end{array}$ & $\begin{array}{l}60 \\
11\end{array}$ & $\begin{array}{r}20 \\
9\end{array}$ & $\begin{array}{l}27 \\
12\end{array}$ & $\begin{array}{r}23 \\
5\end{array}$ & $\begin{array}{r}24 \\
5\end{array}$ & 1 & $\begin{array}{r}16 \\
8\end{array}$ & $\begin{array}{r}30 \\
5\end{array}$ & $\begin{array}{l}37 \\
16\end{array}$ \\
\hline$-u$ & 2 & & 1 & 3 & 1 & & 7 & 14 & 7 & 18 & 20 & 31 & 42 & 16 & 31 & 19 & 20 & 3 & 35 & 35 & 37 \\
\hline $\begin{array}{l}-t a \\
-t e c k k\end{array}$ & 1 & & 14 & 2 & 5 & 4 & 11 & $\begin{array}{l}6 \\
6\end{array}$ & $\begin{array}{l}6 \\
6\end{array}$ & $\begin{array}{r}6 \\
10\end{array}$ & $\begin{array}{r}8 \\
19\end{array}$ & $\begin{array}{l}11 \\
17\end{array}$ & 26 & $\begin{array}{r}13 \\
3\end{array}$ & 14 & 11 & 2 & & 7 & 7 & 12 \\
\hline $\begin{array}{l}\text { - chatza } \\
\text { Words }\end{array}$ & - & & & & & & & & & & 1 & 1 & 5 & 2 & 1 & 4 & 2 & & 2 & 6 & 8 \\
\hline Time since birth (Age) & 1:11 & & & $2 ; 2$ & & & & & & & & $2: 9$ & & & & & & & & & 4:10 \\
\hline
\end{tabular}

Table 3. John's development of Japanese morphology

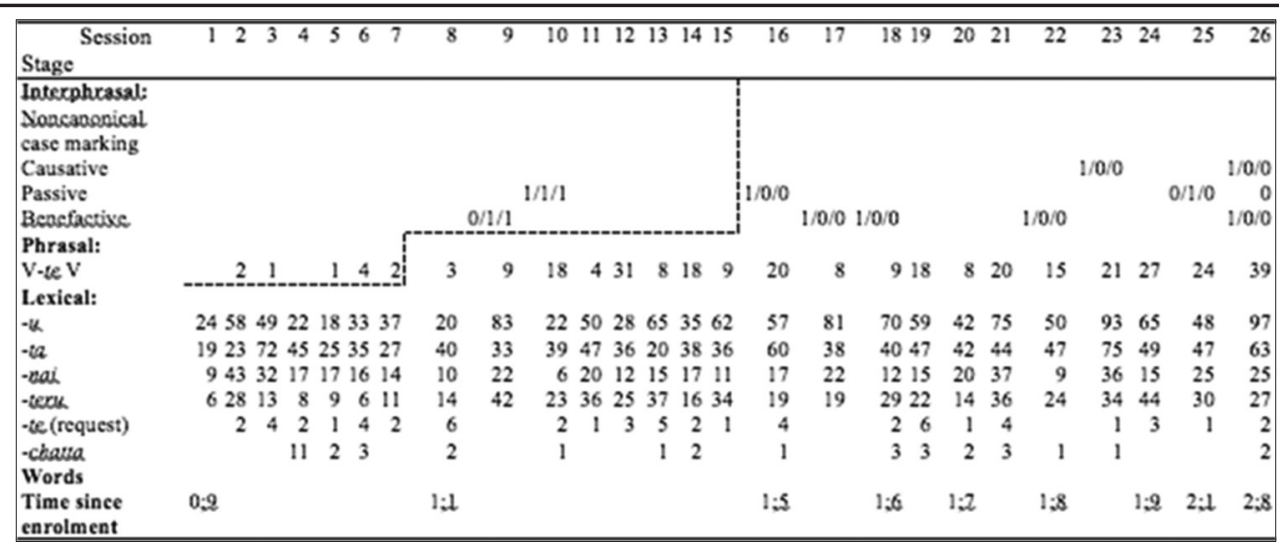


termined. Haru's development of Japanese morphology followed the developmental schedule predicted by PT.

John was already able to produce spontaneous Japanese words when the data collection began, which means that he was already in the Word/Lemma stage. He could produce varieties of verb morphemes with different lexical items during the first data collection session, therefore, the lexical morphology emerged in Session 1. It is possible that he was already at this stage before the data collection began; however, we do not have data to demonstrate this. What we do know is that his lexical morphology emerged at 7;0, nine months after he enrolled in the Japanese school. The phrasal morphology emerged one year and one month after his enrolment, at 7;4. This was followed by the emergence of the interphrasal morphology at $7 ; 8$, one year and five months since his enrolment. The time it took John to arrive at each stage after his enrolment to the Japanese school is expressed using the notation $0 ; 9$ for the lexical morphology, 1;1 for the phrasal morphology and 1;5 for the inter-phrasal morphology, as shown in the last row of Table 3, although they are not his age.

As can be seen from Table 3, John began his interphrasal morphology with the passive structure, followed by benefactive and causative. John's development of Japanese morphology also followed the developmental schedule predicted by PT.

\section{Comparing the Two Types of Acquisition}

We now compare the development of Japanese morphology of Haru and John. With regard to the developmental paths, both children acquired the Japanese morphological structures following the order predicted in PT, i.e., lemma/word $<$ lexical procedure $<$ phrasal procedure $<$ S-procedure. In other words, different types of acquisition did not appear to affect the order of acquisition of morphology in term of processing procedural hierarchy.

However, the rates of acquisition show some differences between the two children. Table 4 below shows the duration each child took to move from one developmental stage of the next. As we do not know how long John took to move from Stage 1 to Stage 2, as he had already reached Stage 2 at the beginning of data collection, we will focus on the time between Stage 2 and Stage 3, and between Stage 3 and Stage 4 . John moved from Stage 2 (at age 7;0) to Stage 3 (at age 7;4), in the space of four months, and then onto Stage 4 (at age $7 ; 8$ ) in another four months. On the other hand, Haru took much longer to progress between the stages; seven months from Stage 2 (at 2;2) to Stage 3 (at 2;9), and another two years to then move to Stage 4 (at $4 ; 10$ ).

Table 4. Duration between developmental stages (months)

\begin{tabular}{lccc}
\hline & $\begin{array}{c}\text { From stage } \\
\text { 1 to stage 2 }\end{array}$ & $\begin{array}{c}\text { From stage } \\
\text { 2 to stage 3 }\end{array}$ & $\begin{array}{c}\text { From stage } \\
\text { 3 to stage 4 }\end{array}$ \\
\hline Haru & 3 & 7 & 25 \\
John & Not known & 4 & 4 \\
\hline
\end{tabular}

There are differences between the two children in terms of the linguistic structures they produced. John produced wider varieties of verb morphemes. Although Table 2 only shows his acquisition of some verb morphemes for an easy comparison with Haru, his data contained productive usage of polite morphemes such as - masu (POL-NONPAST), -mashita (POL-PAST), - masen deshita (POL-NEG-PAST), from Session 2 onwards (Iwasaki 2008). In Haru's data, polite verb morphemes were not present until towards the end of the investigation period. Further, the evidence for both children in Stage 4 is different in both variety and quantity. Haru only expressed benefactive relationship once, and did not express events using passive or causative structures. John produced all the passive, benefactive and causative structures within two years of enrolling in the Japanese school.

\section{DISCUSSION}

This study asked the following research question.

(RQ) do balanced simultaneous bilingual children develop their Japanese verbal morphology in a similar way to successive bilingual children?

The results of this study indicate both the balanced simultaneous bilingual child and the successive bilingual child developed their Japanese morphological structures in identical order, in terms of processing procedural hierarchy as predicted by PT. Past research has established that children who simultaneously acquire more than one language in a balanced manner develop their languages as multiple L1 (e.g., De Houwer 1995; Meisel 2007). However, one of the characteristics of simultaneous bilingual children, is the difference in their individual language learning experiences with regard to such things as the manner, amount of exposure to, and attainment of the language. Because of this, Genesee (2006) notes that it is "risky to identify normative patterns" (p.51) for them. When bilingual children do not develop their multiple languages in a balanced manner, the weaker language is found to develop like adult L2. While previous studies (e.g., Schlyter 1993; Döpke 1996) came to such conclusions by examining the non-L1 like structures produced by bilingual children to see if they also appear in L2 acquisition, this study focused on the acquisition of procedural skills required for realisation of different morphological strucutres. From that point of view, while we remain cautious about generalising from one case study, we argue that balanced simultaneous bilingual abilities develop not only just like L1 but also like L2.

Our results also indicate the differences between the two children in terms of the rate of acquisition, and what they were able to produce. The rate of acquisition of simultaneous bilingual children was often compared with that of monolingual children to see if their linguistic milestones are reached around the same time in terms of age and MLU (Genesee, 2006). For child L2 acquisition, MacSwan and Pray (2005) note that the rate of acquisition is often closely linked to the proficiency level attained by the child; for example, how long each child took to achieve the required proficiency level. In our study, the rate of acquisition is measured by the time each child took to progress from one stage to the 
next of the developmental hierarchy. John, already at school age, progressed faster than Haru to reach each of the stages. The differences in time taken by the two children to move stages, were three months between Stages 2 and 3, and more than one and a half years between Stages 3 and 4. This finding agrees with MacSwan and Pray's (2005) conclusion that "that younger children do not generally learn English faster than older children, as is commonly believed" (p. 670) and that older learners have an advantage in that they "appear to learn faster in the early stages of second language learning", summarised by Lightbown and Spada (2006, P.72). This difference in the rate of progression can be explained by the cognitive state of the two children. For Haru, her cognitive development and language development are happening at the same time, while John had already reached primary school age when he started to first learn Japanese at his Japanese school.

The differences in their age not only mean they are at different cognitive stages, but that they have had different learning experiences with their English. John would most likely have reached Stage 4 in English, prior to learning Japanese. On the other hand, Haru was acquiring English and Japanese simultaneously. In fact, she had only reached Stage 4 in English about one year prior to reaching Stage 4 in Japanese (Itani-Adams 2011, Pienemann, Kessler \& Itani-Adams 2011). In other words, at the time they reached Stage 4 in Japanese, John's English was much more developed as L1 than Haru's. Whether John's high level of English acted as a driving force for him acquiring Japanese at a faster rate is a question outside the scope of this paper.

The variety of verb morphemes the two children produced were of differing qualities. John produced wider varieties of verb morphemes; it is particularly noteworthy that John produced polite morphemes such as - masu (POL-NONPAST), -mashita (POL-PAST), -masen deshita (POL-NEG-PAST) from Session 2, which were lacking from Haru's data until towards the end of period of investigation. This difference may be due to the differences in their linguistic experiences; while they both had naturalistic acquisition, the contexts were different. Haru's Japanese use was confined to her home environment, while John's took place at school, where he would have heard other students interacting with the teachers and other adults. Kawaguchi's (2015) study of instructed university students' L2 Japanese acquisition also shows the production of polite verb morphemes prior to plain forms. The polite form is likely to be used in the instructed language-learning environment. By the same token, learners are likely to need to use polite form in such an environment, and that was probably the case for John.

Not only did it take longer for Haru to reach Stage 4 than John, she also produced limited structural variety and quantity for this stage. Haru only expressed benefactive relationship once, and did not express events using passive or causative structures. John produced all the passive, benefactive and causative structures within two years of enrolling in the Japanese school. The usage of these structures depends on the pragmatic choices the speaker makes, i.e., shifting of focus. These constructions also require a complex mapping of grammar function and discourse (Kawaguchi 2015). The lack of passive and causative structure from Haru's data may indicate that she did not encounter context that required her to focus on the non-agent argument during these early years of her life, or she was not yet cognitively developed enough to use these structures. Monolingual Japanese children are found to not correctly comprehend passive structure until they are older than four, typically five or six years old, and they rely on word order to decode the relationship between arguments rather than on the grammatical particles when they are young (Hakuta 1982; Sano 1977). It can be said that Haru was still at the age where she does not use grammatical particles to encode the relationship between arguments.

To sum up, this study found different rates of acquisition and linguistic varieties and quantities produced by the two children. We pose a question as to whether this provides sufficient evidence to conclude that balanced simultaneous bilingual children do not develop their language in a similar way to successive bilingual children. It is evident that the two children are at different stages of cognitive development, indicated by their age; however, the differences in linguistic varieties and quantities produced may be based on the learning experience and environment they are in. The study found that, despite the difference in the cognitive states and learning experiences, these two children have developed their Japanese through the processing hierarchy in an identical way. From this, our summary of the answer to the RQ 'balanced simultaneous bilingual children develop their Japanese verbal morphology in a similar way to successive bilingual children' is that a balanced simultaneous bilingual child develops their language like a second language in terms of procedural processing, with some variations possibly caused by age, learning experience and environments.

\section{CONCLUSION}

This study addresses the nature of bilingual language development, focusing on the relationships between the simultaneous bilingual and L2. We compare the development of Japanese morphology of a balanced simultaneous bilingual child, with a successive bilingual child who acquired Japanese as L2. The comparison of the development of Japanese morphology by these two children was conducted using the PT analysis framework, as it allowed us to compare these different types of language acquisition using the same point of reference, i.e. processing procedures. The results show that these two children both developed Japanese verbal morphology through the identical developmental schedule predicted by PT. This indicates that balanced bilingual and successive bilingual language acquisition are driven by the same processing procedural skills. It can be said that balanced bilinguals develop their language similarly to L1 and L2 learners. While they developed in an identical sequence, differences were found. The successive bilingual child learnt Japanese at a much faster rate than the balanced simultaneous bilingual child. In addition, he produced wider varieties of structures. We posit that these differences may be due to the different cognitive stages of each of the children, in ad- 
dition to different linguistic experience they encountered in their learning environments. This includes varying levels of English and Japanese input received by each child, as well as the different requirements each had in terms of use of the language.

\section{ACKNOWLEDGEMENT}

We like to thank the participating children and their parents. Without their support this research would not have been possible.

\section{ENDNOTE}

1. Schlyter (1993) examined other structures such as verb finiteness, pronominal subjects, word order and placement of negation.

2. While some literature explain the V-te in the V-te $\mathrm{V}$ structure as gerund (GER) (e.g., Kageyama 1999), we adopt V-COMP as a notation following Di Biase and Kawaguchi (2002) and Kawaguchi (2005, 2010, 2015).

3. The names used for the two children are pseudonyms.

\section{REFERENCES}

Bettoni, C \& Di Biase, B. (Eds.) (2015). Grammatical development in second languages: Exploring the boundaries of Processability Theory. Amsterdam: The European Second Language Association. http://www.eurosla.org/ eurosla-monograph-series-2/eurosla-monographs-03

Bresnan, J. (2001). Lexical-Functional syntax. Malden, MA: Blackwell.

De Houwer, A. (1990). The Acquisition of Two Languages from Birth: A Case Study. Cambridge: Cambridge University Press.

De Houwer, A. (1995). Bilingual language acquisition. In: Fletcher, P. \& MacWhinney, B. (Eds.), The Handbook of Child Language (pp. 219-250). Oxford: Blackwell.

De Houwer, A. (2005). Early bilingual acquisition: focus on morphosyntax and the Separate Development Hypothesis. In J. F. Kroll, \& A. M. B. de Groot (Eds.), Handbook of Bilingualism: Psychological Approaches (pp. 30-48). Oxford: Oxford University Press.

De Houwer, A. (2009). Bilingual First Language Acquisition. Clevedon/Buffalo: Multilingual Matters.

Di Biase, B. \& Kawaguchi, S. (2002). Exploring the typological plausibility of Processability Theory: Language development in Italian second language and Japanese second language. Second Language Research 18(3), 274-302.

Döpke, S. (1992). One Parent - One Language: An Interactional Approach. Amsterdam/Philadelphia: John Benjamins

Döpke, S. (1996). The weaker language in simultaneous bilingualism: Why it is not like L2. Unpublished manuscript. Melbourne: Monash University.

Genesee, F. (2006). Bilingual first language acquisition in perspective. In P. McCardle \& E. Hoff (Eds.), Childhood Bilingualism: Research on infancy through school age (pp. 45-67). Clevedon/Buffalo/Toronto: Multilingual Matters.

Håkansson, G. (2005). Similarities and differences in L1 and L2 development, Opening up the perspective: Including SLI. In: M. Pienemann (Ed.), Cross-linguistic aspects of processability theory (pp. 199-253). Amsterdam/Philadelphia: John Benjamins.

Hakuta, K. (1982). Interaction between particles and word order in the comprehension and production of simple sentences in Japanese children. Developmental psychology, 18: 62-75.

Hulk, A. \& Müller, N. (2000). Bilingual first language acquisition at the interface between syntax and pragmatics. Bilingualism: Language and Cognition 3, 227-244.

Itani-Adams, Y. (2011). Bilingual first language acquisition. In M. Pienemann, \& J.U. Keßler (Eds.), Studying Processability Theory. An Introductory Textbook (pp. 121130). Amsterdam/Philadelphia: John Benjamins.

Itani-Adams, Y. (2013). One child and two languages: Acquisition of Japanese and English as bilingual first languages. München: Lincom.

Iwasaki, J. (2008). Acquiring Japanese as a Second Language (JSL) in a Naturalistic Context: A Longitudinal Study of a Young Child from a Processability Theory (PT) Perspective. Second Language Acquisition and the Younger Learner, 23(13), 231-253.

Jisa, H. (2000). Language mxing in the weak language: Evidence from two children. Journal of Pragmatics 32, 1363-1386.

Kageyama, T. (1999). Word formation. In: Tsujimura, N. (Ed.), The Handbook of Japanese Linguistics (pp. 297-325). Oxford: Blackwell

Kawaguchi, S. (2005). Acquisition of Japanese as a second language: A Processability perspective. Unpublished doctoral dissertation, Sydney: University of Western Sydney.

Kawaguchi, S. (2010). Learning Japanese as a Second Language: A Processability Perspective. Amherst, NY: Cambria Press.

Kawaguchi, S. (2015). The development of Japanese as a second language. In C. Bettoni, \& B. Di Biase (Eds.), Grammatical development in second languages: Exploring the boundaries of Processability Theory (pp. 149-172). Amsterdam: The European Second Language Association. http://www.eurosla.org/eurosla-monograph-series-2/eurosla-monographs-03

Keßler, J.U. \& Keatinge, D. (Eds.). (2009). Research in second language acquisition: Empirical evidence across languages. Newcastle, UK: Cambridge Scholar Press.

Lanza, E. (1997). Language mixing in infant bilingualism: A sociolinguistic perspective. Oxford: Clarendon.

Levelt, W. J. M. (1989). Speaking: From Intention to Articulation. Cambridge: MIT.

Lightbown, P. \& Spada, N. (2006). How languages are learned. Oxford: Oxford University Press.

MacSwan, J. \& Pray, L. (2005). Learning English Bilingually: Age of Onset of Exposure and Rate of Acquisition Among English Language Learners in a Bilingual Education Program. Bilingual Research Journal, 29 (3), 653-678. DOI: 10.1080/15235882.2005.10162857 
Mansouri, F. (Ed.). (2007). Second language acquisition research: Theory-construction and testing. Newcastle, UK: Cambridge Scholar Press.

Meisel, J. M. (Ed.). (1990). Two first languages: Early grammatical development in bilingual children. Dordrecht: Foris.

Meisel, J. M. (2001). The simultaneous acquisition of two first languages: Early differentiation and subsequenst development of grammars. In J. Cenoz, \& F. Genesee (Eds.), Trends in bilingual acquisition (pp. 91-13). Oxford: Blackwell.

Meisel, J. M. (2004). The bilingual child. In T. K.Bhatia \& S.C. Ritchie (Eds.), The handbook of bilingualism (pp. 91-113). Oxford: Blackwell.

Meisel, J. M. (2007). The weaker language in early child bilingualism: Acquiring like a first language as a second language? Applied Psycholinguistics, 28, 495-514.

Mishina-Mori, S. (2002). Language differentiation of the two languages in early bilingual development: A case study of Japanese. International review of applied linguistics, 40, 211-233.

Paradis, J. \& Genesee, F. (1996). Syntactic acquisition in bilingual children. Studies in Second Language Acquisition 18, 1-25.

Pienemann, M. (1998). Language processing and second language development: Processability Theory. Amsterdam/Philadelphia: John Benjamins.

Pienemann, M. (Ed.). (2005). Cross-linguistic aspects of processability theory. Amsterdam/Philadelphia: John Benjamins.

Pienemann, M., Di Biase, B. \& Kawaguchi, S. (2005). Extending processability theory. In M. Pienemann
(Ed.), Cross-linguistic aspects of processability theory (pp. 199-253). Amsterdam/Philadelphia: John Benjamins.

Pienemann, M., \& Keßler, J-U. (Eds.). (2011). Studying processability theory. Amsterdam/Philadelphia: John Benjamins.

Pienemann, M., Keßler, J.U. \& Itani-Adams, Y. (2011). Comparing levels of processability across languages. International journal of bilingualism, 15 (2), 128-146.

Sano, K. (1977). An experimental study on the acquisition of Japanese simple sentences and cleft sentences. Descriptive and Applied Linguistics, Vol. X, 213-233.

Schlyter, S. (1993). The weaker language in bilingual Swedish-French children. In K. Hyltenstam, \& A. Viberg (Eds.), Progression \& Regression in Language: Sociocultural, Neuropsychological \& Linguistic Perspectives (pp. 289-308). Cambridge: Cambridge University Press.

Schlyter, S., \& Håkansson, G. (1994). Word order in Swedish as the first language, second language and weaker language in bilinguals. Scandinavian Working Papers on Bilingualism 9, 49-66.

Sells, P. (1995). Korean and Japanese morphology from a lexical perspective. Linguistic Inquiry, 26, 177-325.

Shibatani, M. (1990). The languages of Japan. Cambridge: Cambridge University Press.

Yip, V. \& Matthews, S. (2000). Syntactic transfer in a Cantonese-English bilingual child. Bilingualism: Language and Cognition 3, 193-208.

Yip, V., \& Matthews, S. (2007). The bilingual child: Early development and language contact. Cambridge: Cambridge University Press. 